\title{
AVALIAÇÃO DE DUAS VARIEDADES DE CANA-DE-AÇÚCAR SUBMETIDAS A DIFERENTES TEMPOS DE ARMAZENAMENTO1
}

\author{
MAURO DAL SECCO DE OLIVEIRA², HUGO TOSI ${ }^{3}$, ALEXANDRE AMSTALDEN MORAES SAMPAIO², \\ PAULO DE FIGUEIREDO VIEIRA ${ }^{3}$ e GILBERTO SANTIAGO ${ }^{4}$
}

\begin{abstract}
RESUMO - Foram estudadas duas variedades de cana-de-açúcar (CO 413 e RB 72 454), com o objetivo de verificar o efeito do armazenamento pós-corte sobre suas características tecnológicas e bromatológicas. As variedades foram cortadas e armazenadas durante zero, 1,5, 3,0 e 4,5 dias. Utilizou-se o delineamento inteiramente casualizado em esquema fatorial $2 \times 4$. A variedade RB 72454 apresentou melhor maturação que a variedade $\mathrm{CO} 413$. O armazenamento proporcionou aumento no teor de açúcares redutores $(\mathrm{P}<0,01)$ e diminuição no teor protéico $(\mathrm{P}<0,01)$ das variedades de cana em estudo. A variedade RB 72454 apresentou maior teor de matéria seca $(\mathrm{P}<0,01)$. Ambas as variedades, quando armazenadas durante 4,5 dias, apresentaram queda de 14,66 e 4,04\% nos teores de proteína bruta e energia bruta, respectivamente.
\end{abstract}

Termos para indexação: Saccharum officinarum, bovino, composição química, nutrição animal.

\section{EVALUATION OF TWO VARIETIES OF SUGAR CANE SUBMITTED TO DIFFERENT STORAGE TIMES}

\begin{abstract}
A study was carried out to investigate the effects of four different storage times on technology and bromatologic characteristics in two sugar cane varieties (CO 413 and RB 72 454). The varieties were cut and stored during zero, 1.5, 3.0 and 4.5 days. It was used a completely randomized design according to a $2 \times 4$ factorial scheme. The RB 72454 variety showed better dry matter level than the $\mathrm{CO} 413$ variety. The storage time increased $(\mathrm{P}<0.01)$ the reducters sugar levels and decreased $(\mathrm{P}<0.01)$ the crude protein levels. When they were stored during 4.5 days, a significative $(\mathrm{P}<0.01)$ reduction of 14.66 and $4.04 \%$ in the levels of crude protein and gross energy, respectively, was observed.
\end{abstract}

Index terms: Saccharum officinarum, bovine, chemical composition, animal nutrition.

\section{INTRODUÇÃO}

A cana-de-açúcar mantém seu valor nutritivo praticamente constante durante o período de maturação, que coincide com a fase de utilização da cultura na época seca do ano; e pesquisas têm

\footnotetext{
${ }^{1}$ Aceito para publicação em 21 de agosto de 1998. Projeto UNESP/Coplana, Guariba, SP.

${ }^{2}$ Zoot., Dr., Dep. de Zootecnia de Ruminantes (DZR), FCAVJ/ UNESP, Rodovia Carlos Tonanni, Km 5, CEP 14870-000 Jaboticabal, SP. Bolsista do CNPq. E-mail: mauro@fcav.unesp.br ${ }^{3}$ Eng. Agr., Dr., DZR, FCAVJ/UNESP.

${ }^{4}$ Eng. Agr., Coplana, CEP 14840-000 Guariba, SP.
}

demonstrado que quanto maior a concentração de sacarose maior o valor nutritivo (Boin, 1984,1985).

Aliado ao grande potencial de produção de matéria seca e de energia, por unidade de área, a cana-de-açúcar tem se destacado entre as principais gramíneas tropicais, porém é pouco estudada principalmente quanto à definição de variedades com características mais adequadas à produção de forragem e ao seu manejo (Preston \& Leng, 1978).

Segundo Banda \& Valdez (1976), com o avanço da maturidade da planta, ocorreu decréscimo nos teores de $\mathrm{N}$ e dos constituintes da parede celular, e aumento nos teores de matéria seca e do conteúdo celular. O aumento do conteúdo celular proporcionado pelo acúmulo da sacarose teve um efeito 
diluidor dos constituintes da parede celular e causou melhor digestibilidade da planta à medida que ela foi amadurecendo.

A variedade RB 72454 apresentou como uma das suas principais características o elevado teor de sacarose (Matsuoka, 1987), no entanto, a CO 413 se destacou, principalmente, como recurso forrageiro, apresentado pelo alto teor de sacarose e baixa porcentagem de fibra.

Com relação à deterioração da cana pós-colheita, Foster \& Irvin (1981) citados por Oliveira et al. (1983) verificaram que a queima provocou significativa perda de fluidos, por ejeção física ou pela exudação do colmo, representando uma redução imediata de 0,3 a 2,6\%. Entretanto, sob fogo severo pode atingir $6 \%$ após o primeiro dia da queimada, porém com queima moderada, as perdas de fluidos foram influenciadas durante vários dias pela absorção de água pelas raízes.

Egan $(1966,1969)$ observou que o processo de deterioração da cana ocorreu no período pós-colheita, por ação das enzimas invertases que degradaram a sacarose em monossacarídeos ou por microrganismos presentes (Leuconostoc spp.), que transformaram e utilizaram a sacarose, produzindo metabólitos de elevado peso molecular, como a dextrana. A ação desses microrganismos ocorreu logo após o corte das plantas e, também, devido às condições úmidas de armazenamento. Nesse sentido, após sete dias da colheita da cana, Parazzi \& Bolsanello (1979) verificaram aumento no teor de açúcares redutores, porém a pureza do caldo e a pol (sacarose) \% tiveram um decréscimo.

Os técnicos da Planalsucar (1984) estudaram a cana crua e a queimada, ambas cortadas inteiras. Verificaram que as médias de açúcares redutores $\%$ cana aumentaram com o transcorrer do tempo; na cana crua os valores acentuaram-se às 48 horas pós-colheita.

Boin (1985) ao estudar algumas variedades de cana-de-açúcar encontrou médias de $0,07 \%$ de fósforo e 3,25\% de proteína bruta na matéria seca. Leng \& Preston (1976) destacaram o baixo teor de lipídios, porém a cana-de-açúcar apresentou digestibilidade relativamente alta. Nesse aspecto, Banda \& Valdez (1976) e Preston \& Leng (1978) verificaram que a digestibilidade da cana-de-açúcar aumentou com o grau de maturação.
Embora a cana-de-açúcar seja uma forragem com potencial para uso na alimentação animal, ainda são necessários estudos sobre as diversas variedades com características mais adequadas à produção e ao seu manejo (Preston \& Leng, 1978).

Segundo Peixoto (1986) para se optar por uma determinada variedade de cana-de-açúcar é preciso levar em consideração aspectos como: valor nutritivo, produção de matéria seca e morfologia da planta.

O objetivo do trabalho foi estudar possíveis alterações em algumas características tecnológicas e na composição químico-bromatológica de duas variedades de cana-de-açúcar submetidas a diferentes tempos de armazenamento, pós-corte.

\section{MATERIAL E MÉTODOS}

Utilizaram-se as variedades CO 413 e RB 72454 obtidas no setor de mudas da Coplana, Guariba, SP. As socas (colmo + ponteiro), das variedades de cana-de-açúcar foram obtidas de segundo corte, sendo 200 de cada variedade, amontoadas em feixes de 30 canas sobre o solo e sem cobertura. Após cada tempo de armazenamento (zero, 1,5, 3,0 e 4,5 dias), foram amostradas, sendo 10 socas retiradas aleatoriamente, de cada repetição/tratamento, para análise química posterior.

As socas foram inicialmente trituradas (triturador de forragem) e, após homogeneização, foram retiradas duas subamostras de $500 \mathrm{~g}$ cada. Uma das subamostras foi prensada em prensa hidráulica a $250 \mathrm{kgf} / \mathrm{cm}^{2}$ por 1 minuto, obtendo-se o caldo e o bolo úmido, conforme metodologia descrita por Tanimoto (1964). A seguir, foram analisados os teores de Brix \% caldo em refratômetro de Brix com leitura corrigida para temperatura padrão de $20^{\circ} \mathrm{C}$ (Copersucar, 1980). Os teores de pol (sacarose) \% cana e açúcares redutores foram obtidos pelo método de Schimitz (1970), citado por Copersucar (1980), e a partir da determinação da glucose foram dosados pelo método volumétrico de Lane \& Eynon (1934), respectivamente. Os coeficientes de pureza aparente da cana (\%), foram obtidos conforme Meade citado por Copersucar (1980), segundo a fórmula: pureza aparente $(\%)=$ pol (sacarose) $\%$ cana / Brix \% cana x 100 .

A outra subamostra foi utilizada para a determinação da composição químico-bromatológica, conforme métodos estabelecidos pela Association of Official Agricultural Chemists (1970). A energia bruta foi determinada em bomba calorimétrica tipo Parr, modelo Ika C-400. Os teores de fibra em detergente ácido e de fibra 
em detergente neutro foram obtidos pelo método de Goering \& Van Soest (1970), citados por Silva (1990).

Para a análise dos dados foi utilizado o delineamento inteiramente casualizado, em esquema fatorial $2 \times 4$ (variedades de cana-de-açúcar $\mathrm{x}$ tempos de armazenamento), com três repetições. Foram determinadas as equações de regressão, pelo método dos polinômios ortogonais, somente para os valores da interação variedades $\mathrm{x}$ tempos de armazenamento, cujo teste de comparação de médias foi significativo.

\section{RESULTADOS E DISCUSSÃO}

Nas Tabelas 1 e 2 são apresentados os dados referentes à análise estatística e as médias dos tratamentos envolvendo os teores de Brix \% caldo, açúcares redutores (AR), pol (sacarose) \% caldo, pol (sacarose) \% cana e pureza aparente.

Pode-se notar que houve diferença significativa nas médias dos parâmetros estudados quanto às variedades. No entanto, com relação aos tempos de armazenamento da cana após o corte, houve significância em Brix \% caldo, açúcares redutores e pureza (Tabela 1). Não foi observada interação entre as variedades e os tempos de armazenamento em pol (sacarose) \% caldo e pol (sacarose) \% cana.

Segundo Brieger (1968) e Leme Junior \& Borges (1970) citados por Serra et al. (1972), para uma qualidade e maturação adequadas, a cana-de-açúcar deve apresentar os seguintes valores mínimos: Brix $\%$ caldo $=18$ e $18 \%$; pol (sacarose) $\%$ caldo $=15,3$ e $14,4 \%$; pol (sacarose) $\%$ cana $=13$ e $16 \%$; pureza aparente $=85$ e $80 \%$; porém para os açúcares redutores valores máximos de 1 e 1,5\%.
Pelas médias apresentadas na Tabela 2, observase que os valores estão dentro dos limites preconizados por Brieger (1968) e Leme Junior \& Borges (1970), citados por Serra (1972). Ressalta-se o elevado teor de pol \% caldo (sacarose) da variedade RB 72 454, média de 17,44\%. Tal valor foi de $16,55 \%$ superior à média obtida na variedade $\mathrm{CO} 413(\mathrm{P}<0,01)$. Tal aspecto foi abordado no trabalho de Carvalho et al. (1993), o qual demonstrou que a cana com maturidade elevada apresentou aumento no conteúdo celular, da matéria seca e sacarose, o que proporcionou um efeito diluidor dos constituintes da parede celular e, em decorrência, maior digestibilidade da planta. Por outro lado, ocorreu queda no teor de nitrogênio com conseqüente queda no teor protéico e dos constituintes da parede celular, que também foi observado por Banda \& Valdez (1976).

Conforme Carvalho et al. (1993), a variedade RB 72454 apresentou média de 12,08 em pol \% cana, e no presente experimento foi obtida média de $14,5 \%$. Comparando-se com a média de 11,91 (CO 413), a superioridade no teor de pol \% cana foi de 21,75\% em favor da variedade RB 72454 $(\mathrm{P}<0,01)$.

Os teores de acúcares redutores foram maiores na variedade $\mathrm{CO} 413$, superando o máximo de $1 \%$ recomendado por Brieger (1968), o que indica a qualidade inferior dessa variedade para o corte. Os açúcares redutores (glicose + frutose), segundo Fernandes (1982), estão diretamente relacionados à maturação. Observou-se que a variedade CO 413 apesar de ter apresentado média semelhante de Brix (sólidos solúveis totais), nos demais parâmetros

TABELA1. Quadrados médios de Brix \% caldo, açúcares redutores, pol (sacarose) \% caldo, pol (sacarose) \% cana, pureza aparente e coeficientes de variação $(\mathrm{CV})$.

\begin{tabular}{lcccccc}
\hline Causas de variação & GL & $\begin{array}{c}\text { Brix \% } \\
\text { caldo }\end{array}$ & $\begin{array}{c}\text { Açúcares } \\
\text { redutores (\%) }\end{array}$ & $\begin{array}{c}\text { pol } \\
\text { (sacarose) } \% \text { (sacarose) } \% \\
\text { caldo }\end{array}$ & $\begin{array}{c}\text { Pureza } \\
\text { aparente } \\
(\%)\end{array}$ \\
\hline Variedades (V) & 1 & $18,20^{* *}$ & $0,72^{* *}$ & $37,25^{* *}$ & $40,09^{* *}$ & $155,44^{* *}$ \\
Tempos de armazenamento (T) & 3 & $0,79^{* *}$ & $0,53^{* *}$ & $0,46^{\mathrm{ns}}$ & $0,41^{\mathrm{ns}}$ & $19,85^{* *}$ \\
Interação V x T & 3 & $1,01^{* *}$ & $0,17^{* *}$ & $0,05^{\mathrm{ns}}$ & $0,08^{\mathrm{ns}}$ & $11,16^{* *}$ \\
Resíduo & 16 & 0,17 & 0,02 & 0,22 & 0,21 & 1,22 \\
\hline CV (\%) & 2,20 & 14,19 & 2,89 & 3,53 & 1,31 \\
\hline ns, ${ }^{* *}$ e Não-significativo e significativo a 5\% e 1\% de probabilidade, respectivamente.
\end{tabular}


houve inferioridade nas médias, demonstrando pior maturação e, portanto, menos indicada para uso na alimentação animal ( $<<0,01$, Tabela 2$)$, haja vista que quanto maior a maturação maior o teor de sacarose. As vantagens obtidas na variedade RB 72454 foram notadas em relação aos teores de pol (sacarose) \% cana, pol (sacarose) \% caldo, açúcares redutores e pureza aparente. Segundo Borba \& Melo (1988) a variedade apresentou valores crescentes de Brix \% caldo, pol $\%$ cana, pol $\%$ caldo e pureza até 16 meses de desenvolvimento vegetativo. Todavia, as médias obtidas no presente experimento demonstraram que após o corte ainda são mantidas as médias, o que não ocorreu com a variedade $\mathrm{CO}$ 413. Mesmo comportamento foi observado por Amin et al. (1972) citados por Oliveira et al. (1983).

Após o corte da cana crua, em ambas as variedades ocorreu queda diária da ordem de 1, 0,21 e $0,15 \%$ nas médias de pureza, sacarose e açúcares redutores, respectivamente, segundo o Geplacea (s.d.) citado por Oliveira et al. (1983) e nas condições climáticas do México.

Apesar de as médias de Brix \% caldo terem sido adequadas, Peixoto (1986) e Carvalho et al. (1993) ressaltaram a importância mínima da maturação da cana para uso na alimentação animal. A variedade RB 72454 apresentou nítido destaque quanto a tais parâmetros. Com relação aos tempos de armazenamento, pode-se notar que apesar da semelhança nas médias de pol \% caldo e pol \% cana, ambas as variedades apresentaram queda na pureza após o corte. Destaca-se o tempo de 4,5 dias como sendo o pior, uma vez que possibilitou a menor média de pureza $(82,59 \%)$. Isso indicou queda acentuada no teor de sacarose em relação aos sólidos solúveis totais. Por outro lado, a partir de três dias de armazenamento, houve maior teor de açúcares redutores, demonstrando a ocorrência da transformação da sacarose em glicose + frutose (Tabela 2).

$\mathrm{Na}$ Tabela 3 estão representadas as equações de regressão da relação entre os teores de Brix \% caldo, açúcares redutores e pureza das variedades de cana-de-açúcar nos diferentes tempos de armazenamento.

Os teores de Brix \% caldo aumentaram linearmente à medida que a variedade $\mathrm{CO} 413$ permaneceu armazenada até 4,5 dias. Entretanto, a equação da variedade RB 72454 apresentou efeito cúbico, ou seja, houve aumento no Brix \% caldo, sendo as médias máxima e mínima de 20,4 e $19,2 \%$ aos 0,61 e 3,2 dias de armazenamento, respectivamente. Mesmo a menor média ainda superou todas aquelas obtidas na variedade $\mathrm{CO} 413$.

Com relação aos açúcares redutores houve aumento nas médias, em ambas as variedades, à medida que aumentou o tempo de armazenamento. A variedade CO 413 e a RB 72454 apresentaram equações quadrática e linear, respectivamente. Segundo o Geplacea (s.d.) citado por Oliveira et al. (1983) o aumento diário no teor de açúcares redutores é em média de $0,15 \%$ na cana armazenada. A variedade RB 72454 apresentou médias dentro do limite máxi-

TABELA 2. Médias de Brix \% caldo, açúcares redutores, pol (sacarose) \% caldo, pol (sacarose) \% cana e pureza aparente das variedades de cana-de-açúcar submetidas aos diferentes tratamentos ${ }^{1}$.

\begin{tabular}{|c|c|c|c|c|c|}
\hline Fatores & $\begin{array}{l}\text { Brix } \% \\
\text { caldo }\end{array}$ & $\begin{array}{c}\text { Açúcares } \\
\text { redutores }(\%)\end{array}$ & $\begin{array}{l}\text { pol (sacarose) } \% \\
\text { caldo }\end{array}$ & $\begin{array}{l}\text { pol }(\text { sacarose }) \% \\
\text { cana }\end{array}$ & $\begin{array}{c}\text { Pureza } \\
\text { aparente }(\%)\end{array}$ \\
\hline \multicolumn{6}{|l|}{ Variedades } \\
\hline $\mathrm{CO} 413$ & $18,22 \mathrm{a}$ & $1,25 \mathrm{a}$ & $14,95 \mathrm{a}$ & $11,91 \mathrm{a}$ & $82,09 a$ \\
\hline RB 72454 & $19,96 \mathrm{a}$ & $0,90 \mathrm{~b}$ & $17,44 b$ & $14,50 \mathrm{~b}$ & $87,18 b$ \\
\hline \multicolumn{6}{|c|}{$\begin{array}{l}\text { Tempos de } \\
\text { armazenamento (dias) }\end{array}$} \\
\hline Zero & $19,00 \mathrm{ab}$ & $0,79 \mathrm{c}$ & $16,50 \mathrm{a}$ & $13,50 \mathrm{a}$ & $86,78 \mathrm{a}$ \\
\hline 1,5 & $18,86 \mathrm{~b}$ & $0,92 \mathrm{bc}$ & $15,83 \mathrm{a}$ & $12,98 \mathrm{a}$ & $83,84 b c$ \\
\hline 3,0 & $18,88 \mathrm{~b}$ & $1,12 \mathrm{a}$ & $16,21 \mathrm{a}$ & $12,98 \mathrm{a}$ & $85,35 \mathrm{ab}$ \\
\hline 4,5 & $19,63 \mathrm{a}$ & $1,47 \mathrm{a}$ & $16,24 \mathrm{a}$ & $13,36 \mathrm{a}$ & $82,59 \mathrm{c}$ \\
\hline
\end{tabular}

${ }^{1}$ Médias seguidas de mesmas letras, dentro da coluna, não diferem entre si pelo teste de Tukey $(\mathrm{P}>0,05)$. 
mo (média de $1 \%$ ), à semelhança dos resultados de Brieger (1968), até o 4,5 dia de armazenamento. Esta variedade demonstrou o mesmo comportamento em relação à pureza, ou seja, as médias máxima e mínima $(89,82$ e $85 \%)$ ocorreram aos 3,38 e 0,96 dias de armazenamento, respectivamente.

A análise da variância e as médias dos nutrientes das duas variedades de cana-de-açúcar submetidas aos diferentes tempos de armazenamento estão expressas nas Tabelas 4 e 5, respectivamente.

Notou-se diferença significativa entre as médias de matéria seca $(\mathrm{P}<0,01)$ e de proteína bruta $(\mathrm{P}<0,01)$ nas variedades estudadas, porém nos demais nutrientes foi observada semelhança $(\mathrm{P}>0,05)$.

Com relação aos tempos de armazenamento, as médias diferiram em teor de proteína bruta $(\mathrm{P}<0,01)$, matéria orgânica $(\mathrm{P}<0,05)$ e energia bruta $(\mathrm{P}<0,01)$.
Não houve interação entre as variedades e os tempos de armazenamento (Tabela 4).

Houve superioridade de $6,13 \%$ na média de matéria seca em favor da variedade RB 72 454, sendo a média de $27,53 \%$ de matéria seca elevada, uma vez que foi superior à média de $25,18 \%$ obtida no trabalho de Carvalho et al. (1993) aos 336 dias de desenvolvimento vegetativo dessa variedade. A média de matéria seca obtida no presente trabalho foi semelhante à média de $27,5 \%$ (proveniente das médias de $29 \%$ de colmos e $26 \%$ de pontas e folhas), obtida por Noa et al. (1992) citados por Walter (1993).

Geplacea (s.d.), citado por Oliveira et al. (1983), encontrou perda diária em peso, na cana cortada crua, de 1,13\%. Com a variedade CO 413, Amin et al. (1972), citados por Oliveira et al. (1983), detectaram perda de peso de 8 a $10 \%$ depois de 4 dias do corte e queima

TABELA 3. Equações de regressão e coeficientes de determinação $\left(\mathbf{r}^{2}\right)$, para Brix \% caldo, pureza aparente, e açúcares redutores das variedades de cana-de-açúcar submetidas aos diferentes tempos de armazenamento ${ }^{1}$.

\begin{tabular}{llc}
\hline Parâmetros & Equações de regressão & $\mathrm{r}^{2}$ \\
\hline Brix \% caldo & $\mathrm{Y}_{\mathrm{a}}=17,640+0,260 \mathrm{X}$ & 0,79 \\
& $\mathrm{Y}_{\mathrm{b}}=20,166+0,826 \mathrm{X}-0,807 \mathrm{X}^{2}+0,141 \mathrm{X}^{3}$ & 1,00 \\
Pureza aparente (\%) & $\mathrm{Y}_{\mathrm{a}}=85,054-1,327 \mathrm{X}$ & 0,93 \\
& $\mathrm{Y}_{\mathrm{b}}=87,900-6,656 \mathrm{X}+4,446 \mathrm{X}^{2}-0,683 \mathrm{X}^{3}$ & 1,00 \\
Açúcares redutores (\%) & $\mathrm{Y}_{\mathrm{a}}=0,875-0,030 \mathrm{X}+0,056 \mathrm{X}^{2}$ & 0,98 \\
& $\mathrm{Y}_{\mathrm{b}}=0,734+0,076 \mathrm{X}$ & 0,93 \\
\hline
\end{tabular}

1 a: variedade CO 413; b: variedade RB 72 454; Y: parâmetro estudado; X: tempo de armazenamento.

TABELA4. Quadrados médios da matéria seca (MS), proteína bruta (PB), fibra em detergente neutro (FDN), fibra em detergente ácido (FDA), extrato etéreo (EE), matéria mineral (MM), matéria orgânica (MO) e energia bruta (EB) da cana-de-açúcar submetida aos diferentes tratamentos e os coeficientes de variação $(\mathrm{CV})$.

\begin{tabular}{|c|c|c|c|c|c|c|c|c|c|}
\hline \multirow[t]{2}{*}{ Causas de variação } & GL & MS (\%) & PB & FDN & FDA & $\mathrm{EE}$ & MM & MO & \multirow{2}{*}{$\begin{array}{c}\text { EB } \\
(\mathrm{kcal} / \mathrm{kg} \mathrm{MS})\end{array}$} \\
\hline & & \multicolumn{7}{|c|}{ 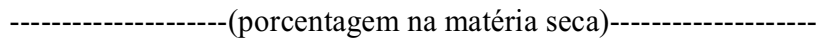 } & \\
\hline Variedades (V) & 1 & $15,08^{* *}$ & $1,23^{* *}$ & $12,71^{\mathrm{ns}}$ & $16,65^{\text {ns }}$ & $0,19^{\mathrm{ns}}$ & $0,11^{\mathrm{ns}}$ & $0,21^{\mathrm{ns}}$ & $68469^{\mathrm{ns}}$ \\
\hline $\begin{array}{l}\text { Tempos de } \\
\text { armazenamento }(\mathrm{T})\end{array}$ & 3 & $1,87^{\mathrm{ns}}$ & $0,18^{* *}$ & $22,67^{\text {ns }}$ & $8,79^{\mathrm{ns}}$ & $0,02^{\text {ns }}$ & $0,46^{\mathrm{ns}}$ & $0,61^{*}$ & $141770^{* *}$ \\
\hline Interação V x T & 3 & $0,56^{\mathrm{ns}}$ & $0,08^{\mathrm{ns}}$ & $24,89^{\mathrm{ns}}$ & $0,98^{\mathrm{ns}}$ & $0,06^{\mathrm{ns}}$ & $0,34^{\mathrm{ns}}$ & $0,38^{\mathrm{ns}}$ & $6486^{\text {ns }}$ \\
\hline Resíduo & 16 & 0,85 & 0,03 & 73,91 & 6,03 & 0,04 & 0,15 & 0,18 & 17221 \\
\hline $\mathrm{CV}(\%)$ & & 3,46 & 7,49 & 20,67 & 9,32 & 19,39 & 29,09 & 0,43 & 3,29 \\
\hline
\end{tabular}


TABELA 5. Médias de matéria seca (MS), proteína bruta (PB), fibra em detergente neutro (FDN), fibra em detergente ácido (FDA), extrato etéreo (EE), matéria mineral (MM), matéria orgânica (MO) e energia bruta (EB) das variedades de cana-de-açúcar submetidas aos diferentes tempos de armazenamento ${ }^{1}$.

\begin{tabular}{|c|c|c|c|c|c|c|c|c|}
\hline \multirow[t]{2}{*}{ Fatores } & MS (\%) & PB & FDN & FDA & $\mathrm{EE}$ & MM & MO & EB \\
\hline & \multicolumn{7}{|c|}{ - } & $(\mathrm{kcal} / \mathrm{kg} \mathrm{MS})$ \\
\hline \multicolumn{9}{|l|}{ Variedades } \\
\hline $\mathrm{CO} 413$ & $25,94 a$ & $2,62 \mathrm{a}$ & $42,31 \mathrm{a}$ & $27,17 \mathrm{a}$ & $1,20 \mathrm{a}$ & $1,43 \mathrm{a}$ & $98,52 \mathrm{a}$ & $3933 \mathrm{a}$ \\
\hline RB 72454 & $27,53 b$ & $2,17 \mathrm{~b}$ & $40,86 a$ & $25,51 \mathrm{a}$ & $1,02 \mathrm{a}$ & $1,29 \mathrm{a}$ & $98,71 \mathrm{a}$ & $4040 \mathrm{a}$ \\
\hline \multicolumn{9}{|c|}{$\begin{array}{l}\text { Tempos de } \\
\text { armazenamento (dias) }\end{array}$} \\
\hline Zero & $26,36 \mathrm{a}$ & $2,66 \mathrm{a}$ & $39,13 \mathrm{a}$ & $27,46 \mathrm{a}$ & $1,11 \mathrm{a}$ & $1,30 \mathrm{ab}$ & $98,67 \mathrm{ab}$ & $3994 a$ \\
\hline 1,5 & $26,28 \mathrm{a}$ & $2,33 b$ & $42,47 a$ & $26,73 a$ & $1,18 \mathrm{a}$ & $1,73 \mathrm{a}$ & $98,18 b$ & $4443 a$ \\
\hline 3,0 & $27,50 \mathrm{a}$ & $2,33 b$ & $43,66 a$ & $26,54 \mathrm{a}$ & $1,03 \mathrm{a}$ & $1,35 \mathrm{ab}$ & $98,64 \mathrm{ab}$ & $4136 a$ \\
\hline 4,5 & $26,80 \mathrm{a}$ & $2,27 b$ & $41,08 \mathrm{a}$ & $24,63 a$ & $1,11 \mathrm{a}$ & $1,06 \mathrm{~b}$ & $98,95 \mathrm{a}$ & $3774 b$ \\
\hline
\end{tabular}

${ }^{1}$ Médias seguidas de mesmas letras, dentro da coluna, não diferem entre si pelo teste de Tukey $(\mathrm{P}>0,05)$.

da cana, sob condições de campo. Todavia, foi observada queda no teor de matéria seca, até 1,5 dias de armazenamento, de apenas $0,3 \%(\mathrm{P}>0,05)$, portanto queda pouco acentuada, independentemente da variedade. Alexander (1973) destacou o efeito do sol, da temperatura, da umidade e do movimento do ar como fatores relacionados com a alteração no teor de matéria seca da cana cortada e armazenada. Geralmente, a redução na qualidade da cana é observada ao longo do armazenamento, com queda nos teores de pureza e de sacarose e conseqüentemente aumento nos teores de açúcares redutores (Parazzi \& Bolsanello, 1979). Nesse sentido, Egan (1966,1969) encontrou em canas cortadas e armazenadas perda de açúcar no caldo e aumento da acidez, devido à ação de Leuconostoc spp. $\mathrm{O}$ fato de a variedade RB 72454 ter apresentado maior teor de matéria seca foi bastante positivo, pois segundo Alvarez \& Preston (1976) quanto maior o teor de matéria seca melhor, uma vez que, aproximadamente, metade da matéria seca da cana é constituída por açúcares.

A variedade CO 413 apresentou uma superioridade de 20,74\% em relação à RB $72454(\mathrm{P}<0,01)$. Entretanto, as médias em teores de fibra em detergente ácido, fibra em detergente neutro e extrato etéreo não foram influenciados estatisticamente
$(\mathrm{P}>0,05)$ tanto pelas variedades como pelos tempos de armazenamento. Os teores de extrato etéreo foram menores ou iguais a $1,18 \%$. Os teores médios de matéria mineral oscilaram em função do tempo de armazenamento $(\mathrm{P}<0,01)$. Tal fato ocorreu pela alteração no teor de matéria seca e, possivelmente, pela proporção de colmo ou pontas + folhas na amostra. Walter (1993) encontrou média de $0,54 \%$ de matéria mineral nos colmos e $2,31 \%$ nas pontas + folhas, o que dá uma média de $1,42 \%$ na cana inteira. Considerando-se os tempos de armazenamento, as médias de matéria mineral oscilaram entre 1,06 a 1,73\%, sendo as médias de 1,43 e 1,29\% obtidas, respectivamente, nas variedades CO 413 e RB 72 454, semelhantes às obtidas no trabalho de Walter (1993).

Devido ao elevado teor de pol (sacarose) \% cana, pol (sacarose) \% caldo e Brix \% caldo, os teores de energia bruta foram altos, mas não foram afetados $(\mathrm{P}>0,05)$ pelas variedades, sendo apenas influenciados pelos tempos de armazenamento.

Observou-se (Tabela 5) que até o 30 dia de armazenamento as médias de energia bruta mantiveram-se superiores a $3.994 \mathrm{kcal} / \mathrm{kg}$ de matéria seca, ou seja, maiores que a média observada quando a cana foi cortada sem ser armazenada. Entretanto, notou-se queda significativa $(\mathrm{P}<0,01)$ no teor médio de energia bruta no $4,5^{\circ}$ dia, cuja média foi de 
$3.774 \mathrm{kcal} / \mathrm{kg}$ de matéria seca. A diminuição observada em relação ao $3 \underline{0}$ e zero dia de armazenamento foi de 14,66 e 4,04\%, respectivamente.

\section{CONCLUSÕES}

1. A variedade RB 72454 apresenta melhor composição químico-bromatológica e melhor maturação que a CO 413.

2. Pode-se armazenar ambas as variedades de cana-de-açúcar pós-corte por até 4,5 dias, ressaltando que após o $3^{\text {o }}$ dia ocorre diminuição no teor energético.

\section{AGRADECIMENTO}

À Coplana (Guariba, SP), pelo auxílio dispensado para as análises laboratoriais e cessão das mudas das variedades de cana-de-açúcar estudadas.

\section{REFERÊNCIAS}

ALEXANDER, A.G. Sugar cane physiology. Amsterdan: Elsevier, 1973. 752p.

ALVAREZ, F.J.; PRESTON, T.R. Studies on urea utilization in sugar cane diets: effect of level. Tropical Animal Production, v.1, p.194-201, 1976.

ASSOCIATION OF OFFICIAL AGRICULTURAL CHEMISTS. Official Methods of Analysis. 11.ed. Washington, DC, 1970. 1015p.

BANDA, M.; VALDEZ, R.E. Effect of stage of maturity on nutritive value of sugar cane. Tropical Annual Production, Ciudad del México, v.1, p.94-97, 1976.

BOIN, C. Cana-de-açúcar: opção na alimentação de ruminantes. Balde Branco, São Paulo, v.105, n.231, p.12-14, 1984.

BOIN, C. Cana-de-açúcar na alimentação de ruminantes. In: D'ARC, R.D.; BOIN, C.; MATTOS, W.R.S. Utilização de resíduos agro-industriais da cana-de-açúcar na alimentação de ruminantes. Piracicaba: FEALQ, 1985. p.19-47.

BORBA, J.M.M.; MELO, F.A.D. Comportamento industrial de diferentes variedades de cana-de-açúcar cultivadas no Estado de Pernambuco. Brasil Açucareiro, Rio de Janeiro, v.106, n.5/6, p.9-14, 1988.
BRIEGER, F.O. Início da safra. Como determinar a maturação. Boletim Informativo Copereste, Ribeirão Preto, v.4, número único, p.1-3, 1968.

CARVALHO, J.G.; ANDRADE, L.A.B.; EVANGELISTA, A.R. Avaliação do potencial forrageiro de cinco variedades de cana-de-açúcar (ciclo de ano) em diferentes estádios de desenvolvimento. STAB, Piracicaba, v.11, n.4, p.18-23, 1993.

COPERSUCAR (São Paulo, SP). Amostragens e análise de cana-de-açúcar. São Paulo: Centro de Tecnologia Copersucar, 1980.37p.

EGAN, B.T. Deterioration problem of chopped cane. Australian Sugar Journal, v.57, n.11, p.922-924, 1966.

EGAN, B.T. Post harvest deterioration losse, in sugar cane in Quensland. Proceedings of International Society of Sugar Cane Technology, v.13, p.1729-1735, 1969.

FERNANDES, A.C. Comportamento agroindustrial de seis variedades de cana-de-açúcar (Saccharum spp.) com e sem fertiirrigação. Piracicaba: ESALQ, 1982. 82p. Tese de Mestrado.

LANE, J.H.; EYNON, L. Determination of reducing sugar by fehlings solution with methylene blue indicator. London: Norman Rodge, 1934. 8p.

LENG, R.A.; PRESTON, T.R. Sugar cane for cattle production: present constraints, perspectives and research priorities. Tropical Animal Production, v.1, n.1, p.1-26, 1976.

MATSUOKA, S. RB 72 454: uma variedade de cana-deaçúcar para todo o Brasil. Brasil Açucareiro, Rio de Janeiro, v.105, n.4/6, p.8-18, 1987.

OLIVEIRA, C.G. de; STURION, A.C.; MELO, F.A.D.; GEMENTE, A.C.; PRATA, R.M. Estudo sobre a perda de qualidade da cana-de-açúcar do campo à unidade industrial a nível de diferentes estratos de produção, no Estado de Alagoas. STAB, Piracicaba, v.13, n.6, p.48-53, 1983.

PARAZZI, C.; BOLSANELLO, J. Estudos preliminares de deterioração de cana-de-açúcar, na região de Campos. In: CONGRESSO NACIONAL DA SOCIEDADE DE TÉCNICOS AÇÚCAREIROS DO BRASIL, 1979, Maceió. Anais... Maceió: STAB, 1979. p.489-492.

Pesq. agropec. bras., Brasília, v.34, n.8, p.1435-1442, ago. 1999 
PEIXOTO, A.M. A cana-de-açúcar como recurso forrageiro. In: CONGRESSO BRASILEIRO DE PASTAGENS, Piracicaba, 1986. Anais... Piracicaba: FEALQ, 1986. p.17-47.

PLANALSUCAR (São Paulo, SP). Relatório Anual, Piracicaba, SP, 1984. 166p.

PRESTON, T.R.; LENG, R.A. La caña de azucar como alimento para los bovinos parte I: limitaciones nutricionales y perspectivas. Revista Mundial de Zootecnia, v.27, p.7-12, 1978.

SERRA, G.E.; CESAR, M.A.A.; OLIVEIRA, A.J.; GODOY, D. Comportamento de variedades de cana-de-açúcar no período de industrialização. Brasil Açucareiro, Rio de Janeiro, v.79, n.4, p.27-40, 1972.

SILVA, D.J. Análises de alimentos: métodos químicos e biológicos. 2.ed. Viçosa, MG: UFV-Imp. Univ., 1990. $165 \mathrm{p}$.

TANIMOTO, T. The press method of cane analysis. Hawaiians Planter's Record, v.57, n.2, p.139-150, 1964.

WALTER, A.C.S. Potencial energético da cana-de-açúcar. STAB, Piracicaba, v.11, n.4, p.29-34, 1993. 